\title{
Learning the Whole Game of Shabbat
}

Joseph Reimer

$W$

hat does Shabbat at camp look like, when viewed through the eyes of a learning theorist? In this chapter, Reimer calls our attention to the way in which Shabbat at camp is a practice with its own norms and behaviors, some related to Shabbat elsewhere but many of which are distinct, into which younger students are inducted over time. On the other hand, a comparison to the theatre program at camp reveals the limitations of the present induction model for Shabbat. Reimer concludes with some recommendations for how Shabbat at camp might be designed more aspirationally. Beyond the specifics of the case, however, Reimer helped us to see how a particular Jewish educational setting may benefit from an analysis that is grounded in a theory of learning.

At 6:15 p.m. every Friday ... a miracle happens.

Everyone in camp is in the same place, at the same time...

We are all dressed in our finest summer threads; and with that well-known approving smile of our director ... the community opens their siddurim and begins to chant "Yedid Nefesh."

Celebrating Shabbat at Jewish summer camps is a great triumph for Jewish education in North America. How often have Jewish educators designed a Jewish ritual celebration that has taken hold in virtually all non-profit residential Jewish camps? For all its varieties, Shabbat at camp is broadly recognizable. A vast majority of these camps ${ }^{2}$ have incorporated these features: preparing for Shabbat, Friday evening services, a festive meal followed by

1 Stacey Cohen, "Reflections," in Ramah at 60: Impact and Innovation, ed. Mitchell Cohen and Jeffrey S. Kress (New York: National Ramah Commission, 2010), 333.

2 These camps are the non-profit overnight camps in North America that self-identify as Jewish camps. Jdata follows the growth of these camps. One can see that data for 121 such camps at www.jdata.com on March 6, 2012. 
singing and dancing, a relaxed Shabbat schedule, and a Havdalah ceremony to close the day. ${ }^{3}$

The Shabbat memory cited above is from an alumna of a Ramah camp. If we were to collect comparable memories from alumni of other Jewish camps, surely the details of celebration would differ, but the general contours might not be so varied. One way to view Shabbat at summer camps is to suggest that more non-orthodox Jewish youth in North America are likely to experience a full day of Shabbat in camp than in any other context in their lives.

There is much we do not know about Shabbat at camp-about the variation of Shabbat practices at the diverse camps, or how staff members guide their campers to experience Shabbat, ${ }^{4}$ or what campers actually learn from participating in this special day and how it affects them afterwards. But in this chapter, I will investigate how camp educators could design Shabbat at camp to enhance how campers and staff learn the practices of Shabbat.

Why? As a scholar of Jewish camps who has regularly visited camps to observe their practices ${ }^{5}$ I am deeply impressed by the power of the Shabbat celebrations I have witnessed. At the same time, I am also convinced that most Jewish camp educators have yet to systematically consider the rich learning potential that Shabbat at camp represents. But the purpose of the chapter actually goes beyond camp itself. I want to propose that Shabbat at camp is an instance of a particular kind of learning environment. Were we to better understand the relationship between participating in a communal ritual like Shabbat at camp and the learning from that participation, we could enhance Jewish learning across many other Jewish educational settings.

\section{Perkins' Theory of Learning by Wholes}

One reason Jewish educators have yet to realize the full educational potential of Shabbat at camp is that the questions involved have yet to be properly conceptualized. Amy Sales and Leonard Saxe ${ }^{6}$ have put forward the dominant

3 Amy L. Sales and Leonard Saxe, "How Goodly Are Thy Tents": Summer Camps as Jewish Socializing Experiences (Hanover, NH: Brandeis University Press, 2004).

4 Zachary Adam Lasker, "The Camp Counselor as Educator and Role Model for Core Jewish Values and Practices of the Conservative Movement" (EdD diss., University of California Los Angeles, 2009).

5 Joseph Reimer, "Vision, Leadership, and Change: The Case of Ramah Summer Camps," Journal of Jewish Education 76, no. 3 (2010), 246-71; Joseph Reimer, "Providing Optimal Jewish Experiences: The Case of Camp Ramah in Wisconsin," Journal of Jewish Education 78, no. 2 (2012), 114-34.

6 Sales and Saxe, "How Goodly Are Thy Tents." 
paradigm for how the structural features of camp life set up the possibilities for new learning, a "socialization" model according to which counselors and staff socialize campers into camp practices. They help us appreciate how a young and non-professional staff of counselors can help further the camp's educational agenda. But what the socialization paradigm lacks is a theory of learning within a camp setting: how children between the ages of nine and sixteen make sense of their camp experience and learn from their participation in the essential features of camp life. There is yet much theoretical and empirical work to be done in exploring campers' learning.

To begin that work, we might turn to David Perkins. As a cognitive scientist and educational theorist, Perkins is primarily interested in how to educate for a deeper understanding of whatever subject or area one is presenting. Perkins ${ }^{7}$ observes that educators often settle for a shallow version of what constitutes understanding. They are willing to allow learners to repeat a few phrases or answer a few set questions as if that demonstrated their understanding. The cost of settling is that too often learners walk away believing they have learned a subject when in fact, were you to ask them to use their knowledge in another context, they would prove unable to do so. Their knowledge is inert. By contrast when educators design opportunities for learners "to perform their understanding" by drawing on what they have learned to respond to a variety of questions that arise from a variety of frameworks, there is a much greater chance that those learners will attain both a deeper understanding and a better capacity to apply what they have learned to situations outside that specific learning setting.

In his more recent work, Perkins ${ }^{8}$ asks what it means to understand something deeply. When he asked his students when they felt they understood something deeply, most pointed to life situations outside their schooling. That was a huge clue: to understand what best promotes deeper understanding, Perkins had to start with life situations outside of formal education.

Perkins' personal answer was that he felt that deeper understanding when he was learning to play baseball as a child, and he uses the example of baseball to great effect.

I enjoyed playing and learning. In a more analytic sense, it was pretty good because from the beginning I built up a feel for the whole game. I knew

7 David Perkins, Smart Schools: Better Thinking and Learning for Every Child (New York: The Free Press, 1992).

8 David Perkins, Making Learning Whole: How Seven Principles of Teaching Can Transform Education (San Francisco: Jossey-Bass, 2009). 
what hitting or missing the ball got you. I knew about scoring runs and keeping score. I saw how it fit together. ${ }^{9}$

"How it fit together" is the key phrase. Often, especially in school, young learners do not see how it all fits together. They learn this and that, but lack an integrative frame that helps to put it all together. And without that whole framework there can be no deep understanding. "Learning by wholes" stresses that building that whole framework is essential for deep learning to proceed.

And so, Perkins invites educators to design "whole games," games that promote learning by wholes, that help to initiate learners into the disciplines that these educators represent. What draws Perkins to games as his central metaphor is not that they are fun to play. Rather, they provide a structured way to introduce beginners into a whole activity that makes sense to the players, engages their interest, and motivates them to keep improving their level of performance. What matters in learning baseball is not simply that the players enjoy playing and want their team to win, but that they may be motivated to do more-to attend batting practice to work on their swing, for example, so that when the time comes, they might knock in the winning run.

Perkins argues that the best way to initiate new learners into any complex domain is by immediately involving them in playing a simplified version of the whole game. When coaches get kids out on a baseball field, they do not wait until the novices have mastered the basics of hitting and fielding before allowing them to play. Quite the opposite: the novice players start playing at their beginner level and get excited about being part of the game. They gain a feel for how the game is played and can see that what they are doing can lead to playing like their older peers. Only when that basic framework has been established do the coaches work on improving their skill level.

The whole game approach overlaps with what many have called "experiential learning." 10 But Perkins goes beyond common approaches to "experiential education" by asking that educators build into these whole games features that derive from cognitive science. For if adults simply let children play these

9 Ibid., 2.

10 David Bryfman, "Experiential Jewish Education: Reaching the Tipping Point," in International Handbook of Jewish Education Part Two, ed. Helena Miller et al. (London: Springer, 2011), 767-84; Joseph Reimer and David Bryfman, “Experiential Jewish Education,” in What We Now Know About Jewish Education: Perspectives on Research for Practice, ed. Roberta Louis Goodman et al. (Los Angeles: Torah Aura Productions, 2008), 343-52. 
games, the learners will learn the basics and get a feel for the game, but may not get much better at the skills of the game. Perkins is aiming for the design of whole games where, by using "the principles of learning"11 that he has identified, educators will promote deeper learning opportunities to give learners the confidence to play with increasing skill, understanding, and flexibility.

\section{Shabbat at Camp as a Whole Game}

Most Jewish educators would agree that it is hard to teach about Shabbat to learners who have never experienced a Shabbat. ${ }^{12}$ The great advantage of Shabbat education at a residential Jewish camp is that even the new campers get to live Shabbat each week. I would call living Shabbat a "whole game" for at camp there are clear practices and rules that everyone knows and that defines "celebrating Shabbat." What is crucial is that by playing a whole game, the novice gets a tacit sense of the whole experience, learns its rules, becomes proficient at its practices, and senses the enjoyment of being part of a group that celebrates Shabbat together.

By calling Shabbat a whole game, I have no intention of reducing what is holy to the level of the mundane. But since my interest is in how campers learn to participate in the celebration of Shabbat, I am positing that for many campers learning how to celebrate may not be much different than learning how to participate in other all-camp activities. In this respect, learning to do Shabbat is no different than learning how to do Color War when it "breaks out." You get with the flow, stay alert to the directions, and follow the crowd until you get the hang of the activities.

Perkins' image of learning to play a whole game recalls Jean Lave and Etienne Wenger's ${ }^{13}$ well-known description of learning in a community of practice as "legitimate peripheral participation." Jewish camps function as communities of practice; by starting to participate in the practices of this community, novice campers learn what they will need to know to become fuller participants in this camp culture. Part of that is how to participate in the weekly rituals of celebrating Shabbat. But "learning by wholes" goes beyond

11 Perkins, Making Learning Whole, 9.

12 Isa Aron, "Visionary Learning: Schooling for Everyone," in Sacred Strategies: Transforming Synagogues from Functional to Visionary, ed. Isa Aron et al. (New York: Rowman and Littlefield, 2010), 77-114.

13 Jean Lave and Etienne Wenger, Situated Learning: Legitimate Peripheral Participation (New York: Cambridge University Press, 1991). 
"legitimate peripheral participation" and points to the way to a more ambitious approach to learning.

Consider the following. Let's imagine that after two seasons at a Jewish camp, ${ }^{14}$ most campers have become fairly adept at participating in the rituals of Shabbat at camp. They know the routine. They know when to stand and sit at services and how to sing along with the tunes. They have learned to enjoy the Friday night celebrations and the more relaxed pace of Saturdays at camp. They even look forward to the Havdalah ceremony that caps the Sabbath day. They have learned all this through their legitimate peripheral participation during their first two summers.

If so, what comes next? For the many campers who attend for multiple summers, what do they learn from participating in Shabbat once they have mastered the basic routines? My hypothesis is that their learning curve has flattened out. They are happy to repeat the same patterns each week. From the perspective of the socialization model proposed by Sales and Saxe, ${ }^{15}$ this repetition is good when it reinforces that participating in Jewish life can be a pleasurable aspect of their lives. But there is precious little new learning happening, within the domain of Shabbat, as campers return for four to six summers and even, for some, go on to become staff.

Need Jewish camp educators settle for this minimal level of Jewish learning or might they aim for more? While one cannot set a single set of aims for diverse Jewish camps, some camps may aim to create Jews who in diverse ways will want to build a Shabbat practice for their adult lives. They may want to teach campers not just to be participants but to be more, to become competent practitioners of Shabbat rather than just amateur players. For my purposes, it is not important what competence in the domain of Shabbat looks like, and it may look different from camp to camp. But I am suggesting that Perkins offers an alternative model that could lead to redesigning Shabbat at camp so that campers have the opportunity to deepen their learning of Shabbat and are better prepared to take that learning into their future lives.

\section{Junior Versions of Whole Games}

The primary way to enrich an educational program in Perkins' view is by the educators' designing successive “junior versions” of the whole game.

14 A season at camp lasts from as short as ten days for younger campers to eight weeks for older campers. Four weeks is probably the modal season.

15 Sales and Saxe, "How Goodly Are Thy Tents." 
The junior version is less technically demanding. The timelines are much shorter. The activity often substitutes simulations for the real thing. . . However, these junior versions capture a range of basic structural features of the whole game... [and] involve learners meaningfully in whole games from the beginning. ${ }^{16}$

In introducing learners to any complex domain, there is a long road to travel from being a novice to becoming a competent practitioner, much less an expert. Perkins ${ }^{17}$ proposes that to help learners to progress beyond the elemental versions, educators should design a set of instructional steps or "junior versions," each of which captures crucial elements of the whole and allows the learners to play the game at a level of complexity appropriate for their level. While Perkins offers examples of educators who in school settings have managed to do this, the structure of schooling actually makes it quite difficult. By contrast we can point to multiple examples in camp. For example, at a welldesigned waterfront, the campers try out new practices and learn new skills in a set of steps that helps them to become more competent and confident in swimming and boating. Each step is a "junior version" in the sense that the children are actually swimming or boating, but each one is a designed instructional step that allows the children to gain greater competencies.

What often goes unarticulated is that both the waterfront educators and the campers share an implicit vision of what this whole game looks like, and hence, what an adult who has gained the requisite skills in swimming and boating can do in the water. Moreover, not only do they share a vision of what an adult version of the whole game looks like, but in addition, it is taken for granted than many adults will keep using their swimming and boating skills in life contexts outside of camp. So no one asks the question: Why are we investing so much in getting these children to develop these competencies?

The same applies to learning in sports and the arts. In well-developed camp programs there are sports and arts faculty who are adept at teaching these skills in what can be called "junior versions" and who have an implicit idea of what this whole game entails and what it would look like for a camper to become increasingly competent in that domain. As the campers gain greater competence, they move to a next level of participating where more is asked and the game looks increasingly like what competent adults play.

16 Perkins, Making Learning Whole, 37.

17 Ibid. 
But what is the comparable example in camp for mastering new Jewish skills? I have seen Ramah camps where some of the oldest campers have become competent in Torah reading. I have seen Union for Reform Judaism (URJ) campers where some of the oldest campers have become competent in song leading. But as compared to developing skills in sports or at the waterfront, there are only a handful of campers who develop these Judaic skills while the majority of campers do not. Indeed many camps do not have any junior versions where fourteen-year-old campers are challenged to learn new Judaic competencies. They are only asked to repeat what they already learned at camp in their first couple of summers. ${ }^{18}$

Historically there were Jewish camps that were founded with clear visions of how the campers would grow in the camp's chosen Jewish competencies. ${ }^{19}$ But today, in most Jewish camps, there is no progressive acquiring of defined skills that have application to living rich Jewish lives outside of camp. In these camps the analogue between learning to play sports and learning to celebrate Shabbat has broken down. Most campers know that the skills they build on the camp's athletic fields can be used in their home communities, and are actually used by some adults. But they may not know adults who regularly celebrate Shabbat and cannot imagine their families would use the Shabbat competencies that they learn at camp. So why would they exert effort to become more skilled at celebrating Shabbat?

Some Jewish camp educators have struggled with the social distance between the Jewish life they create at camp and the Jewish lives that most live the rest of their lives. ${ }^{20}$ But they have been lacking what Perkins offers: an educational approach to prepare learners to become more skilled in the practices of Shabbat so they could, if they wished, adapt those to other contexts in their lives.

Before investigating how Perkins' approach to whole learning could lead Jewish camp educators to restructure aspects of Shabbat celebration, let me turn to a model camp program that I have studied that exemplifies designing

18 Clear exceptions to this observation can be found at URJ Camps: the Chalutzim program at OSRUI and Jewish leadership program at Kutz Camp.

19 Jenna Weissman Joselit, A Worthy Use of the Summer: Jewish Summer Camps in America (Philadelphia: National Museum of American Jewish History, 1993); Hillel Gamoran, "The Road to Chalutzim: Reform Judaism's Hebrew-Speaking Program," in A Place of Our Own: The Rise of Reform Jewish Camping, ed. Michael M. Lorge and Gary Phillip Zola (Tuscaloosa: University of Alabama Press, 2006), 27-51.

20 Michael Zeldin, "Making the Magic in Reform Jewish Summer Camps," in Lorge and Zola, A Place of Our Own, 27-51. 
successive junior versions of a whole Jewish game: theatre education at Camp Ramah in Wisconsin.

\section{Theater Education at Camp Ramah in Wisconsin}

Since 2008, I have been studying one camp, Ramah in Wisconsin, in greater depth to better understand how they integrate Jewish education into their larger camp program. My focus has not been on Shabbat, but on theatre education. I was drawn to their Jewish theatre program for it exemplifies how a camp arts program can be transformed into an exciting vehicle for Jewish creative expression. ${ }^{21}$

When thinking about Perkins' approach, I realized that the theatre program could be revisited as a model for designing successive junior versions of the whole game of Jewish theatre. As background, let me quote selections from my earlier paper.

For decades the Ramah camps have had the tradition of staging American Broadway musicals in Hebrew. This tradition accords with the original Ramah vision of placing great emphasis on both the arts and the Hebrew language (Fox, 1997). What better way for campers to appreciate the possibilities of Modern Hebrew than to learn in Hebrew the lines of plays they already know well in English?

At Ramah Wisconsin veteran director Rabbi David Soloff recognized that the traditional Ramah drama program had grown tired, and yet was not prepared to jettison the staging of the Broadway musicals in Hebrew. Soloff decided to invest more heavily in growing the camp's drama staff, diversifying the drama program at camp as well as revivifying the traditional Hebrew production. ${ }^{22}$

What drew my attention in my earlier research was how, in the production of a single Hebrew musical, the coordinated staff effort created for the campers a powerful optimal Jewish experience. ${ }^{23} \mathrm{I}$ had never before seen such a large group of young teens so taken up and excited about performing a musical in Hebrew. I wondered how the camp managed to create that kind of excitement when most of the campers do not even understand the

21 Reimer, "Providing Optimal Jewish Experiences," 114-34.

22 Reimer, "Providing Optimal Jewish Experiences," 115-16.

23 Mihaly Csikszentmihalyi, Flow: The Psychology of Optimal Experience (New York: HarperCollins, 1990); Reimer, "Providing Optimal Jewish Experiences." 
Hebrew they are singing. For the present, though, I am focusing not on any single play but on the succession of theatre experiences in which many campers participate over an extended period of time. What matters from Perkins' perspectives is not how powerful any one learning experience might be, but how the sequence is structured so that campers have multiple opportunities to be immersed at one level and then move on to a more complex level. This theatre program provides campers over the course of seven years with the following successive steps of involvement, or what we can now call "junior versions."

1. For their first two years younger campers serve as audience for the performances of their older peers while also being introduced to theatre at their own level.

2. During their first summers on the camp stage twelve- and thirteenyear-olds are initiated into performing their first Hebrew musical that tends to be simpler with easier music to sing.

3. During the next two summers that division of campers will perform each year a more complex Hebrew musical.

4. At age fourteen, some campers will also work with staff to perform a weekly Shabbat mini-performance called Storahtelling, which is a dramatic commentary in English on the weekly Torah portion.

5. At age fifteen, some campers will also work with the drama staff to help put on the "Tikvah play," the Hebrew play that the special needs campers perform.

6. At age sixteen, during their final summer as campers, the oldest division will perform what the camp staff considers to be the most complex of the Hebrew musicals.

7. In addition some of the oldest campers will volunteer to work intensively on both writing and acting in an original play in English that they will perform before several camp audiences. ${ }^{24}$

This menu of opportunities involves virtually all the campers whatever their skill levels in some aspect of Jewish theatre. Only a small number of campers can star in a feature role in a Hebrew musical. But those musicals are designed to create many different avenues for involvement so that even campers who will never be able to sing a solo will have an active role. And the English drama piece for the oldest campers opens the door to campers who

24 J. A. Ross, Personal Interview, 2014. 
have interest in drama, but no fluency in Hebrew or singing ability. It gives those oldest campers an unprecedented opportunity to create their own play that helps them reflect on what this camp experience has meant to them as they end their time as campers.

Note how this sequence of theatre experiences is structured. Starting out as part of the audience is an essential first step. It allows the younger campers to be legitimate peripheral participants while they develop an appetite for the camp stage. By the time of their first turn on a camp stage, they are ready to perform in Hebrew. The camp staff monitors each group, selects a play that they can manage and modifies the script to meet their needs. It is a big challenge to perform in Hebrew, but the campers know this is the camp tradition and their staff will not let them fail. This menu of theatre opportunities illustrates how a camp implicitly creates successive junior versions of a whole Jewish game.

\section{From Theatre to Shabbat at Camp}

The theatre program at Ramah Wisconsin evolved gradually and deliberately to answer three questions:

- How to involve virtually all the campers in producing a Hebrew play when the campers' Hebrew abilities are so varied;

- How to keep this process interesting and challenging over the five summers that most campers participate in these Hebrew plays;

- How to offer those campers with more serious interests in theatre varied opportunities to perform not limited to the Hebrew musicals. ${ }^{25}$

Let me raise three parallel questions that could guide the redesign of Shabbat celebration at many Jewish camps.

- How can Shabbat at camp be designed to actively engage virtually all the campers given that often campers come from varied Jewish backgrounds?

- How can Shabbat at camp remain challenging and interesting to campers who have already been at camp for a few summers and know well the routines of the communal celebration?

- How can the camp offer those campers who have a more serious interest in Jewish practice the opportunities to develop their Jewish skills through an enhanced participation in Shabbat at camp?

25 Reimer, "Providing Optimal Jewish Experiences," 114-34. 
Imagine a camp staff taking apart their Shabbat celebration and asking: How can we redesign the component parts so that we can facilitate greater camper participation and learning? When a camp has many campers who do not have much prior experience with celebrating Shabbat, there is a temptation at Shabbat services to ramp up the music, simplify the Hebrew and shorten the event to minimize camper resistance. Perkins, however, offers an alternative conception: you can always make a junior version even "more junior." 26 Perkins distinguishes "more junior" from simplified. The former entails a clear conception of what the whole looks like and the imaginative capacity to offer virtually any learners entry to that whole, but at a level where they can have access.

How might that be done for campers with little prior background? It entails creating services that are elemental in their simplicity but not fragmented, so that they remain representative of the whole game of Shabbat. It entails studying what is overwhelming and incomprehensible to novices about the all-camp celebrations and offering them a taste of the all-camp services that they can enjoy before feeling overwhelmed. It entails learning occasions before Shabbat at which counselors allow the novices to practice the few prayers, songs, and dances they will perform on Shabbat_- not to learn about Shabbat, but to practice some of the elements, in the way that a father might take his daughter out to the park to field a few grounders or to take some swings before starting T-ball. It entails preparing counselors to be aware of the discomfort that campers might experience and ready to model the expected practices and answer the questions that arise.

\section{Keeping Shabbat Interesting and Challenging}

What would this look like? When campers reach age thirteen it is an ideal time for camp educators to approach them with a new message. "Now that you have already celebrated your bar or bat mitzvah and spent a few summers at camp, it is time to go deeper in your Jewish learning. We will challenge you as a group to explore new learning. We will challenge you as a group to explore new ways to celebrate Shabbat. Much of what you love about Shabbat at camp will remain unchanged, but you will be challenged to do Shabbat in new ways."

Imagine, then, that celebrating Shabbat at camp could have distinctive shifts such that when these campers move on to a next division, the way they participate in Shabbat would grow more complex. Beginning with the available

26 Perkins, Making Learning Whole, 40. 
resources that most Jewish camps have to redesign Shabbat, here are two examples for redesigning Shabbat.

Music and dance: Within camp some songs are reserved only for Shabbat. That creates wonderful educational opportunities. Imagine that the music and dance staffs decided to assign each division its own new songs and dances that were special to them and that expressed their growing competencies. The campers in that division would intensively learn these new songs and dances during the first week of camp and they could become their signature pieces. On Shabbat, they would be the ones to lead in that singing or dancing piece. They would know these pieces well and be proud to display their mastery. These presentations could enliven services and be presented at other points during the day.

Theatre and movement: Shabbat is a wonderful occasion for campers to express their creative dramatics and movement. Younger children might dramatize different Jewish folk tales. Older campers could dramatize short stories from Jewish authors. Yet other campers could explore a set of movements that expresses what it means to rest on Shabbat or to greet the Sabbath queen. Campers in a division would choose a medium of expression and work with that medium for their time at camp, each week exploring another aspect of the Shabbat experience.

The goal is to turn Shabbat celebration from an automatic set of rituals that everyone knows to a set of challenges that communicates clearly, "You still have much to learn about Shabbat, and camp provides a wonderful set of opportunities to deepen that learning." The principle is to prepare the staff to help the older campers make Shabbat their own in ways that allow them to reflect on and enact an understanding of Shabbat that is meaningful for them. The analogue is to the English play that oldest campers stage at Ramah Wisconsin. The play is their own creation and provides an opportunity for these adolescents to reflect seriously on what means most to them as they look ahead to the years beyond being campers.

Or consider another example, that emerges from the history of the URJ camps, where there is a tradition of older campers taking an active role in planning "creative services" for Shabbat. ${ }^{27}$ That is a wonderful basis for thinking about how to turn "creative" into "creative and skilled." This has already taken place with song leading. Now older adolescents from these camps can attend

27 Donald M. Splansky, "Creating a Prayer Experience in Reform Movement Camps and Beyond," in Lorge and Zola, A Place of Our Own, 151-72. 
workshops where they can learn the skills of effective song leading. Imagine if camps offered similar workshops in leading Israeli dance, Jewish storytelling and giving dvar Torah. Imagine if specialists worked with the older campers to give them opportunities to try out their new skills in camp and then bring those skills to other venues during the year where Shabbat is celebrated. Imagine if the consistent message of the last years at camp was, "You can contribute to creating a richer Shabbat experience at camp that you can also carry home with you."

A basic premise of Perkins' work is that creating successive junior versions allows learners not only to more deeply understand the domain they are exploring but to also have the flexibility to transfer that understanding to contexts other than the ones in which the learning takes place. Perkins is not thinking about summer camps and the difficulties of bringing home what you learn at camp. But his work suggests ways to think about how camp educators could redesign the Jewish learning at camp to heighten the possibility of adaptation to other contexts. We know campers cannot take the bunk or lake or camp spirit home with them. But skills are more transportable. When camp educators focus more on developing transportable Jewish skills, they increase the chances that some of those skills could find expression outside the confines of summer camp.

\section{Conclusion: Learning from Skill Building}

Throughout this paper I have been walking a fine line of recognizing the power of Shabbat at camp and yet calling for a basic redesign of those experiences. I have been drawing on Perkins ${ }^{28}$ theory of learning by wholes to show that the Shabbat celebrations that might work well as socializing experiences may work less well to promote the deeper understanding that campers will need to adapt what they learned about Shabbat to their lives outside of camp.

The questions considered in this paper have applicability beyond the context of Jewish camps. "Jewish camp” can represent any immersive Jewish learning experience that takes place in a dedicated space for a defined time. Whenever Jewish educators create such learning environments, they face the same learning problems we have explored in this paper. In particular they face the question of how can participants take home some of what they learned in this special context.

28 Perkins, Making Learning Whole. 
As Perkins argues, taking learning home does not happen of its own accord. Many educators continue to believe that when they create powerful learning experiences, learners will so appreciate the "transformative" quality of the experience that they will be motivated to take their learning home. But evidence points in the opposite direction. What Perkins holds out is a slim reed of hope that educators could redesign learning environments so there is a greater focus on the successive learning and practicing of Jewish skills. We want our youth to enjoy participating in these wonderfully rich experiences. But we also want some of them to think, "I could learn how to lead this song or dance or service and bring that back to my home community." For in the Jewish community much rests upon the possibility that what happens at camp does not stay at camp. 


\section{Bibliography}

Aron, Isa. "Visionary Learning: Schooling for Everyone." In Sacred Strategies: Transforming Synagogues from Functional to Visionary, edited by Isa Aron, Steven M. Cohen, Lawrence A. Hoffman, and Ari Y. Kelman, 77-114. New York: Rowman and Littlefield, 2010.

Bryfman, David. "Experiential Jewish Education: Reaching the Tipping Point." In International Handbook of Jewish Education Part Two, edited by Helena Miller, Lisa Grant, Alex Pomson, 767-84. London: Springer, 2011.

Cohen, Stacey. "Reflections." In Ramah at 60: Impact and Innovation, edited by Mitchell Cohen and Jeffrey S. Kress, 332-33. New York: National Ramah Commission, 2010.

Csikszentmihalyi, Mihaly. Flow: The Psychology of Optimal Experience. New York: Harper Collins, 1990.

Dolgin Katz, Betsy. "Reflections." In Ramah at 60: Impact and Innovation, edited by Mitchell Cohen and Jeffrey S. Kress, 354-55. New York: National Ramah Commission, 2010.

Gamoran, Hillel. "The Road to Chalutzim: Reform Judaism's Hebrew-Speaking Program." In A Place of Our Own: The Rise of Reform Jewish Camping, edited by Michael M. Lorge and Gary Phillip Zola, 27-51. Tuscaloosa: University of Alabama Press, 2006.

Joselit, Jenna Weissman. A Worthy Use of the Summer: Jewish Summer Camps in America. Philadelphia: National Museum of American Jewish History, 1993.

Lasker, Zachary Adam. "The Camp Counselor as Educator and Role Model for Core Jewish Values and Practices of the Conservative Movement." EdD diss., University of California Los Angeles, 2009.

Lave, Jean, and Etienne Wenger. Situated Learning: Legitimate Peripheral Participation. New York: Cambridge University Press, 1991.

Lerner, Stephen C. "Ramah and its Critics." Conservative Judaism 25, no. 4 (1971), 1-28.

Perkins, David. Making Learning Whole: How Seven Principles of Teaching Can Transform Education. San Francisco: Jossey-Bass, 2009.

"What is Understanding?" Teaching for Understanding: Linking Research with Practice, edited by Martha Stone Wiske. San Francisco: Jossey-Bass, 1998. Smart Schools: Better Thinking and Learning for Every Child. New York: The Free Press, 1992. 
Reimer, Joseph, and David Bryfman. "Experiential Jewish Education." In What We Now Know About Jewish Education: Perspectives on Research for Practice, edited by Roberta Louis Goodman, Paul A. Flexner, and Linda Dale Bloomberg, 343-52. Los Angeles: Torah Aura Productions, 2008.

Reimer, Joseph. "Providing Optimal Jewish Experiences: The Case of Camp Ramah in Wisconsin." Journal of Jewish Education 78, no. 2 (2012), 114-34.

"Vision, Leadership, and Change: The Case of Ramah Summer Camps." Journal of Jewish Education 76, no. 3 (2010), 246-71.

Ross, J. A. Personal Interview. 2014.

Sales, Amy L., and Leonard Saxe. "How Goodly Are Thy Tents": Summer Camps as Jewish Socializing Experiences. Hanover, NH: Brandeis University Press, 2004.

Sales, Amy L., Nicole Samuel, and Matthew Boxer. Limud by the Lake Revisited: Growth and Change at Jewish Summer Camp. New York: AVI CHAI Foundation and CMJS, 2011.

Splansky, Donald M. "Creating a Prayer Experience in Reform Movement Camps and Beyond." In A Place of Our Own: The Rise of Reform Jewish Camping, edited by Michael M. Lorge and Gary Phillip Zola, 151-72. Tuscaloosa: University of Alabama Press, 2006.

Zeldin, Michael. "Making the Magic in Reform Jewish Summer Camps." In A Place of Our Own: The Rise of Reform Jewish Camping, edited by Michael M. Lorge and Gary P. Zola, 27-51. Tuscaloosa: University of Alabama Press, 2006. 